\title{
Las cuadrillas de presos: constructores tradicionales en los caminos de la modernización. Valle del Cauca 1912-1915*
}

\author{
Por Fanny Constanza Gómez Villarreal ${ }^{* *}$
}

\begin{abstract}
Resumen
Las cuadrillas de presos, usadas para dotar de obreros a las vías que debían permitir el avance del Valle del Cauca hacia la modernización, se presenta como una gran ironía, en la cual una figura de orígenes coloniales, se convierte en una herramienta del moderno siglo XX. Indagar sobre las razones que permitieron su supervivencia al interior del recién fundando departamento del Valle entre 1912-1915, conocer si se trataba de una estrategia económica o hacia parte de la política criminal del Estado, cuáles fueron las entidades que reglaban ésta actividad, las condiciones de trabajo a las que fueron sometidos los reos, los beneficios jurídicos que acarreaba participar como obrero en las cuadrillas de presos y la percepción que la comunidad dirigente de la época tenía sobre la eficacia de las labores desempeñadas por los presidiarios, son algunos de los interrogantes que se pretenden disipar al interior de ésta investigación.
\end{abstract}

Palabras claves: modernización, Valle del Cauca, cuadrillas de presos.

\begin{abstract}
The gangs are, used to provide workers to the way that should allow the progress of the Valle del Cauca toward modernization, is presented as a great irony, in which a figure of colonial origins, becomes a tool of the modern century $X X$. Investigate the reasons that allowed their survival into the newly founded department of Valle between 1912-1915, to know if it was an economic strategy or to part of the criminal justice policies, which were the institutions that govern this activity, the conditions work to which prisoners were subjected, the legal benefits that derive participate as workers in the crews of prisoners and the perception that the community leader of the era had on the effectiveness of the work performed by inmates, are some of the questions that are intended to dissipate within this research.
\end{abstract}

Keywords: modernization, Valle del Cauca, prisoners.

Este estudio tomó forma como parte del proceso de catalogación del Archivo Histórico de la Gobernación del Valle del Cauca, emprendido por la Gobernación y el Programa de Historia de la Universidad del Valle. Se ubica en el período que va de 1912 a 1915, buscando comprender las razones que permitieron la participación de los presos en la construcción de caminos y obras públicas o "cuadrillas de presos", el porqué de su uso, si con ello se buscaba obtener mano de obra barata, o si hacía parte de una estrategia de

\footnotetext{
"Artículo tipo 2, de reflexión según Colciencias. Articulo creado a partir del trabajo de grado para optar al título de historiadora.

*** A bogada de la U. Santiago de Cali, Historiadora de U. del Valle, Investigadora Grupo REGION - U. del Valle.Correo: fannycgomez@gmail.com.
} 
aplicación de la justicia, motivada por los lineamientos de la política criminal estatal.

El análisis de las cuadrillas de presos, nos lleva a dar una ojeada en los primeros años del departamento del Valle y su inicial desarrollo administrativo, porque fue una figura que funcionó con la participación de varias instituciones estatales en formación, como: la Cárcel, las secretarías de Hacienda, de Obras públicas y de Justicia principalmente, permite entonces, revisar no sólo las políticas y fines que guiaron a las administraciones departamentales, sino percibir hasta qué punto se encontraban cohesionadas entre sí y ligadas a la modernización institucional que se pretendía alcanzar desde el gobierno central.

\section{Un gobierno centralista y modernizador}

El nacimiento del Valle como departamento, hizo parte de las intenciones centralizadoras del Estado, presentes en el Gobierno desde 1886, pero sólo se cristalizaron durante el gobierno de Rafael Reyes (1904-1909) ${ }^{1}$, quien buscaba ante todo impedir acciones de corte separatista, como lo ocurrido con Panamá, dada la capacidad de desequilibrio político presente entre las elites Caucanas. Pero también fue una respuesta a la aparición de subregiones de importancia económica, dentro del extenso territorio caucano, como ocurrió en el Quindío, con el afianzamiento del cultivo del café unido a la importancia de Cali, en la agroindustria cañera y de Buenaventura como un muelle exportador.

A partir de la constitución de 1886 de marcada política centralizadora, el Estado colombiano empieza a fortalecer y ampliar la influencia de sus instituciones sobre las actividades económicas y sociales efectuadas en su territorio, con la finalidad de alcanzar el sueño de la modernización, a través de la inserción del país en la economía internacional.

Con el crecimiento nominal y funcional del estado, se buscó crear nuevas formas de construcción social, a través de dos procesos: "Uno, centralizar en el Estado o al menos hacer públicas las funciones y servicios destinados a la población; otro, transformar la asistencia social cambiando la caridad por la filantropía; es decir, empezar a tratar la pobreza como objeto de inversión" (Saenz, Saldarriaga, et all., 1997, p. 414).

Se buscó entonces, crear un sistema de instrucción pública basado en principios religiosos y morales, que buscaba la orientación práctica, en la agricultura, las ciencias naturales y la ingeniería, con el fin de impulsar el progreso económico. En las regiones, esta prioridad recayó en manos de los Gobernadores departamentales, a quienes la Ley les entregó la responsabilidad de fomentar y vigilar los establecimientos educativos, al tiempo que les imponía el deber de impulsar las obras públicas departamentales: desde la construcción de vías de comunicación hasta escuelas y cárceles; pero siempre guiándose por las metas y proyectos aprobados desde el Gobierno central (Diario Oficial, N 14974, 22 de febrero de 1913).

\footnotetext{
${ }^{1}$ La segmentación progresiva del Cauca, llevada a cabo entre1904- 1910, permitió además la aparición de los departamentos de Chocó, Nariño, Caldas, Quindío y Putumayo.
} 
La administración departamental empieza durante este período a enfocarse cada vez más en la construcción de vías de comunicación, como resultado del desarrollo comercial de Cali y del Suroccidente.

Se buscó entonces, consolidar por fin los proyectos de modernización económica planeados desde finales del siglo XIX, como la construcción de la vía férrea al puerto de Buenaventura obra que determinó la vocación de la región, construida a lo largo de 42 años y concluido en 1914 (Flórez, 1997, p. 35) y el mejoramiento del camino de Cali-Palmira, vistos por la dirigencia regional como obras que traerían no sólo un bienestar económico, acompañado de inmejorables condiciones para la industria y el comercio, al mismo tiempo, permitirían alcanzar un mayor nivel de tranquilidad social que alejara el fantasma de los enfrentamientos partidistas del pasado (Valencia, 1993, p. 107).

Para alcanzar sus fines, el gobierno regional enfocó sus prioridades en dotar de recursos al recién fundado departamento, con el aumento de las rentas sobre el tabaco y el licor, organizando toda la burocracia encargada de recolectar y administrar los recursos, al tiempo que intentaba reforzar las instituciones de control y represión como la fuerza de policía y la construcción de cárceles en las principales ciudades del departamento como Cali, Buenaventura y Palmira, que todavía no tenían sedes propias (Archivo Histórico Gobernación del Valle, Tomo 77, p. 9).

\section{Las cuadrillas de presos}

La búsqueda de la integración regional con los mercados externos, hizo crecer la demanda de la mano de obra necesaria para la construcción de las vías de comunicación y demás proyectos financiados por el Estado, exigiendo cada vez mayor calificación en los trabajadores. A pesar de ello, entre 1911 -1916 se hizo evidente la continuidad del uso de mano de obra poca calificada, proveniente de tradiciones heredadas del siglo anterior, como el trabajo personal subsidiario (trabajo en obras públicas de cobro anual) ${ }^{2}$ y las cuadrillas de presos.

Esta figura venía siendo utilizada desde la colonia, como una herramienta óptima para contrarrestar la escasez y dispersión de la mano de obra en los territorios de la región, permitiendo la construcción de caminos y vías, donde los vagos y entretenidos eran puestos a disposición de las autoridades municipales para que efectuaran obras de importancia para la comunidad, como lo menciona Zamira Díaz al referirse al uso de mano de obra esclava e indígena, en la construcción de la ruta Cali-Popayán: "En efecto todos aquellos indígenas que cometían delitos, en general robos, eran asignados a las obras públicas, urbanas o rurales" (Díaz, 1983, p. 28).

\footnotetext{
${ }^{2}$ El trabajo personal subsidiario se ocupaba de: “... 1.el mantenimiento de los edificios públicos. 2. continuación de obras empezadas como locales de escuelas, cárceles, etc. 3. composición y mantenimiento de los caminos más transitados, apertura de nuevos...". VALENCIA Llano Alonso. Estado soberano del Cauca, Federalismo y Regeneración. Banco de la República. Bogotá, 1988. pp.101 y 102
} 
La aparente contradicción, entre la búsqueda por la modernización de las costumbres sociales y económicas, frente a la continuidad de una forma de trabajo basada en principios coloniales, nos lleva a preguntarnos cuál era la misión que se le estregaba a las cárceles según la política criminal del momento y si existieron motivaciones económicas para hacer del uso de mano de obra sujeta, en este caso presidiarios, en la construcción de los caminos y rutas del Valle del Cauca.

\section{La política criminal como formadora de ciudadanos}

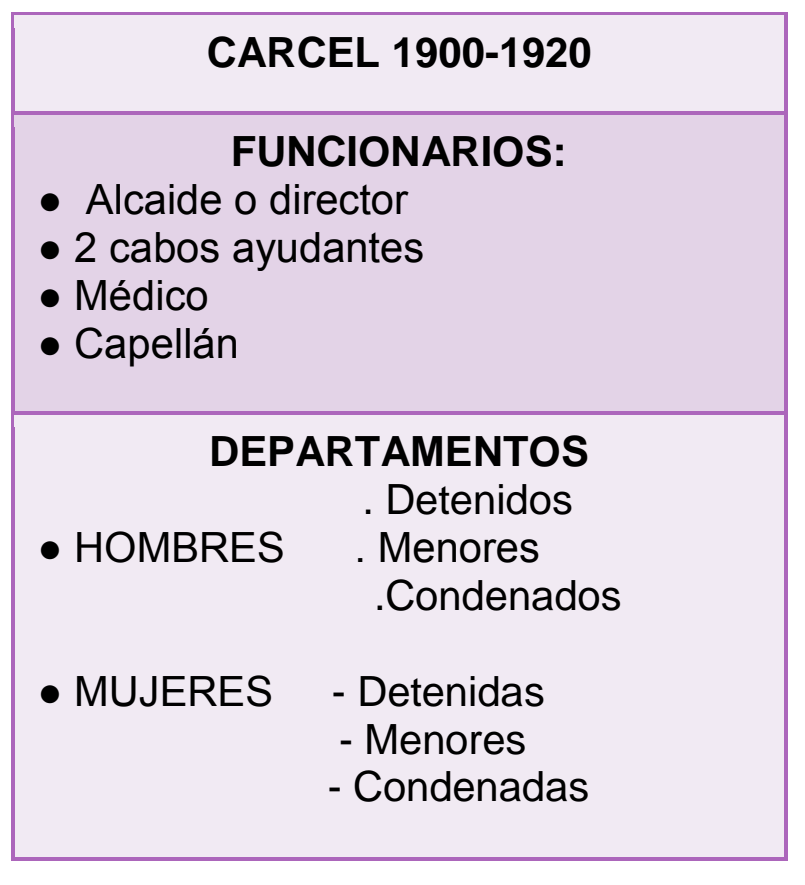

Imagen $\mathrm{N}^{\circ} 1$ : Composición de las cárceles

La modernidad llegó a la legislación penal, mediante el Proyecto de Código Penal elaborado por José Vicente Concha en $1912^{3}$, esta nueva codificación hizo uso de las teorías más recientes seguidas en Italia e Inglaterra, marcadas por los postulados Positivistas y Humanistas que señalaban a las características etnográficas y al carácter de las civilizaciones, como elementos determinantes a la hora de elaborar la legislación de un estado, unido al objetivo correccional, reformador y utilitario que se le otorgaba a la pena.

La reforma penitenciaria estaba inspirada "en el sistema irlandés de William Crofton ${ }^{4}$, que combina la prisión celular ${ }^{5}$ con otras medidas encaminadas todas

\footnotetext{
${ }^{3}$ Realizado durante el gobierno de Carlos E. Restrepo (1910-1914).

${ }^{4}$ Capitán Crofton, irlandés que popularizó la aplicación del sistema progresivo, basado en la ejecución progresiva de la pena, que permitía una posible reducción hasta en una tercera parte de acuerdo a la conducta y al trabajo del penado. Aunque en la cita se hace referencia a William Crofton, el nombre del creador del sistema progresivo fue Walter Crofton y William Penn fue quien estableció el sistema pensilvánico, Tomado de http://www.inpec.gov.co/contenido.php?pagina=90 nov. 30 de 2005.

${ }^{5}$ Sistema Celular O Pensilvánico: consideró que la pena privativa de la libertad bajo vigilancia constante, podía ser útil para que el infractor se reconciliara con Dios y la sociedad, basándose en la higiene severa y el trabajo como recogimiento y señal de arrepentimiento. Tomado de http://www.cddhcu.gob.mx/camdip/comlvii/comelegs/inicio/PonenEdos/Chis/07-019.html $25 \quad \mathrm{de}$
} 
al mejoramiento del individuo sometido a la pena y a procurar que vuelva a ocupar la posición que antes tenía... permite que se sufra la condena en una colonia agrícola o en un establecimiento especial, o en trabajos públicos" (Concha, 1924, pp. $10-11$ ).

Con la adopción de éste sistema, se pretendía hacer de la cárcel una institución modeladora del carácter y la conducta de los infractores, buscando que lograran readaptarse a las expectativas que la sociedad tenía sobre ellos y que al final pudiesen desempeñar su propio rol dentro de la comunidad.

El código penal de Concha buscaba integrar al país a:

Los sistemas penitenciarios modernos [que] rechazaban la pena de muerte y los castigos por considerarlos "horrores jurídicos y asesinatos legales", veían a la prisión como la mejor herramienta para modelar un nuevo ciudadano y su efectividad como un triunfo del Estado y su poder de regulación y modificación de conductas (Caimari, 2002, p. 147).

Con este fin, la legislación estableció la opción de entregar conocimientos mínimos a los penados a través de clases de religión, lectura, escritura y aritmética, con una duración de cuatro horas diarias, siempre y cuando la población carcelaria lo solicitara y la penitenciaría contara con los recursos necesarios para implementar las clases (Gaceta Departamental, № 281, Marzo 16 de 1913). En 1914 se crea la Dirección General de Prisiones, pero la falta de una política penitenciaria no permite que las cárceles cumplan con los requisitos estipulados en la ley. El siguiente cambio legislativo importante, queda plasmado en el Decreto 1405 de 1934, a través del cual se determina la presencia al interior de las cárceles de dotaciones escolares, industriales, higiénicas y sanitarias, estableciendo un importante cambio en la búsqueda por transformar a los detenidos en ciudadanos rectos y útiles.

Al seguir estas directrices, nuestra legislación penitenciaria se inscribía en el esquema de construcción de sociedades disciplinadas descritas por Michel Foucault, en la cual la prisión es una institución correctora por medio del trabajo y la moral (Foucault, 1981).

En esta perspectiva, el trabajo hacía parte de la vida de un retenido, no como simple castigo, sino como mecanismo de corrección y transformación dirigida, hacia la ciudadanía activa. Cuando un preso o un prisionero trabajaban, era visto como una señal de corrección en su conducta, trayendo consigo una remuneración o un beneficio, que podía ser la rebaja de pena o la calificación de "buena conducta".

El cambio de legislación trajo aparejado la consolidación de una estructura burocrática al interior de las penitenciarias, que pretendía construir un sistema que reglamentara la división de presos por: género, clase de agresión, trabajo a seguir y disciplina.

noviembre de 2005 y en http://noticias.juridicas.com/areas/65-Derecho\%20Procesal\%20Penal/10Art\%EDculos/199907-afv05 02.htm noviembre 30 de 2005. 


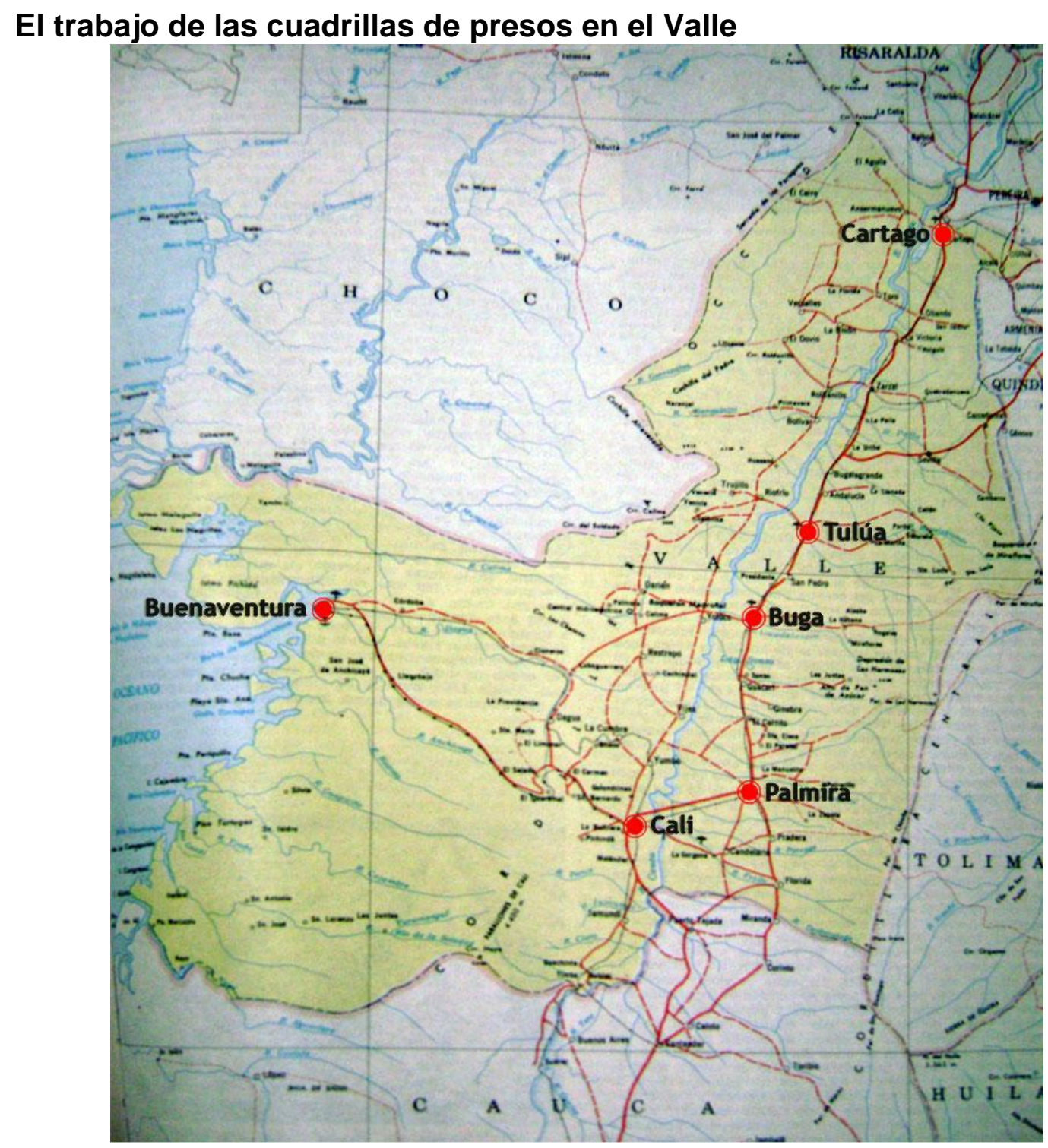

Imagen $\mathrm{N}^{\circ}$ 2: Penitenciarías del Valle del Cauca, 1911

Para 1911, se estableció la penitenciaría de Cali, además de este lugar de reclusión, el recién fundado departamento del Valle contaba con las penitenciarías de Buga, Tulúa, Cartago, Buenaventura y Palmira. Pero en Cali existía un mayor número de población presidiaria (para 1913 superaba las 120 personas entre detenidos y procesados) (AHGV, Tomo 77, p. 9), fueron estos reos los usados para conformar las cuadrillas de trabajo que intervinieron en una buena cantidad de las obras que se adelantaban en torno a la capital del Valle.

Las labores de las cuadrillas de presos se concentraban en los caminos municipales y departamentales, en algunas ocasiones también participaban en la construcción y reparación de vías interurbanas. Entre algunas de las obras realizadas en 1911 - 1915 con la participación de presos, podemos mencionar: Reparación de la vía Yotoco - Huasanó (AHGV, Tomo 77, p. 9), Camino Cali Ansermanuevo (AHGV, Tomo 5, fol. 174 -175), Mejora del Camino de Yumbo - 
Ansermanuevo (AHGV, Tomo 5, fol. 218 - 220), Vía interurbana de Cali, y carretera al sur (Flórez, 1997, p. 138). De acuerdo a las disposiciones legislativas, sólo podían participar en las labores los presos y detenidos hombres acusados de delitos comunes, las mujeres no eran cobijadas por la norma, tampoco estaban obligados a trabajar en las obras públicas los menores de 15 años (AHGV, Ordenanza N ${ }^{\circ} 35$ de 1915, p. 551).

El horario fue fijado de 6 a 10 de la mañana y de 12 a 4 de la tarde, las labores se llevaban a cabo de lunes a sábado (AHGV, Tomo 5, fol. 138 - 139), generalmente las cuadrillas se encargaban de actividades como el aplastamiento, corte de contra-fuertes, desagües y puentes (AHGV, Tomo 5, fol. $218-220)$.

Las cuadrillas estaban guiadas por un "sobrestante" o capataz encargado de dirigir el trabajo de los presos en la obra, llevar la cuenta del número de horas trabajadas por cada penado y la actividad que realizaban, las tareas eran designadas según los planes del Ingeniero del Departamento, quien se encargaba de la dirección de las obras emprendidas por la Gobernación.

\section{Pago de raciones y beneficios por trabajo}

Las leyes fijaban el pago de una ración diaria para todos los presos pobres, está ración era aumentada si el individuo privado de la libertad trabajaba, ese aumento dependía de las horas laboradas y de las actividades realizadas, cuando el penado cumplía la labor que le había sido asignada y continuaba con otra diferente, su buena disposición le merecía una paga extra.

Estos beneficios eran otorgados por la gobernación, cuando los presos los solicitaban. Se estimaba sobre todo la clase de tarea realizada, aquellas que se consideraban más valiosas podían ser equivalentes a mayor trabajo, además se decretó que: "La gobernación tendrá en cuenta para apreciar la buena conducta de los que soliciten rebaja de pena, el amor que hayan mostrado por el trabajo durante la detención" (AHGV, Tomo 5, fol. 138 -140).

El pago de las raciones para los presos provenía de una asignación prevista en el presupuesto del Departamento del Valle, entregada al Departamento de Justicia y pagadas por los Administradores Provinciales De Hacienda, previa solicitud hecha por los Alcaldes municipales. El pago efectivo, era llevado a cabo por los Alcaides o Directores de las penitenciarias.

Las raciones se pagaban diariamente a cada preso, dividendo el pago así: en la mañana, se entregaba la ración fijada por la ley a los presos pobres y en la tarde, después de ser cumplida la jornada de trabajo se otorgaba el aumento de la ración a los penados que cumplían con su servicio en las obras públicas (AHGV, Tomo 5, fol. 138 - 139).

La reglamentación de los pagos a presos fue abundante, establecían no sólo el valor de las raciones y las autoridades encargadas, sino también los controles que debían seguirse para determinar la entrega del pago a cada penado. Por ejemplo, se señalaba el deber del "sobrestante" para establecer las horas 
trabajadas por cada preso, a través de un informe previo al pago de las raciones, además se determinaba que la entrega del dinero debía llevarse a cabo con la presencia del Administrador Provincial de Hacienda, en cada penitenciaria, llamando a lista a cada preso, previamente formada una fila frente a los pagadores (AHGV, Decreto $N^{\circ} 51$, febrero 8 de 1913).

\section{Guardianes}

La vigilancia de las cárceles y la conducción de los presos desde el presidio hasta el lugar de la obra, estaba en manos de la policía, ellos debían encargarse de vigilarlos durante el desempeño de sus funciones e impedir cualquier tipo de disputas entre los presos, o agresiones contra los transeúntes y los demás trabajadores (AHGV, Ordenanza № 29, 26 de marzo de 1912).

Esta reglamentación pone de manifiesto cómo eran vistos los presos por la sociedad, mostrándonos, que a pesar de ser empleados en labores que buscaban contribuir a la mejora de la vida comunitaria, no se olvidaba la razón de su condena y seguían siendo percibidos como personas peligrosas, que no debían tener contacto con los transeúntes y mucho menos con sus guardias.

La nutrida legislación concerniente al trabajo realizado por las cuadrillas de presos demuestra, la existencia de un interés más allá del simple cumplimiento de la política criminal estatal, que percibía a este tipo de trabajadores como una herramienta viable y competitiva, para avanzar en la construcción de la infraestructura pública de comunicaciones. Al parecer, esta idea fue compartida por un amplio grupo de la dirigencia regional, desde la creación del departamento y los subsiguientes cinco años, como se refleja en un informe presentado por la Secretaria de Gobierno en 1913, en el cual se alababa el trabajo de presos en las obras públicas al ser visto como: "Medida salvadora que naturalmente tendió a que los presos no permanecieran en las cárceles sin ocupación y a favorecer el mejoramiento de los capitales de provincia con un costo pequeño pero no de escasa representación para el progreso material de nuestras ciudades" (AHGV, Tomo 77, p. 9). 


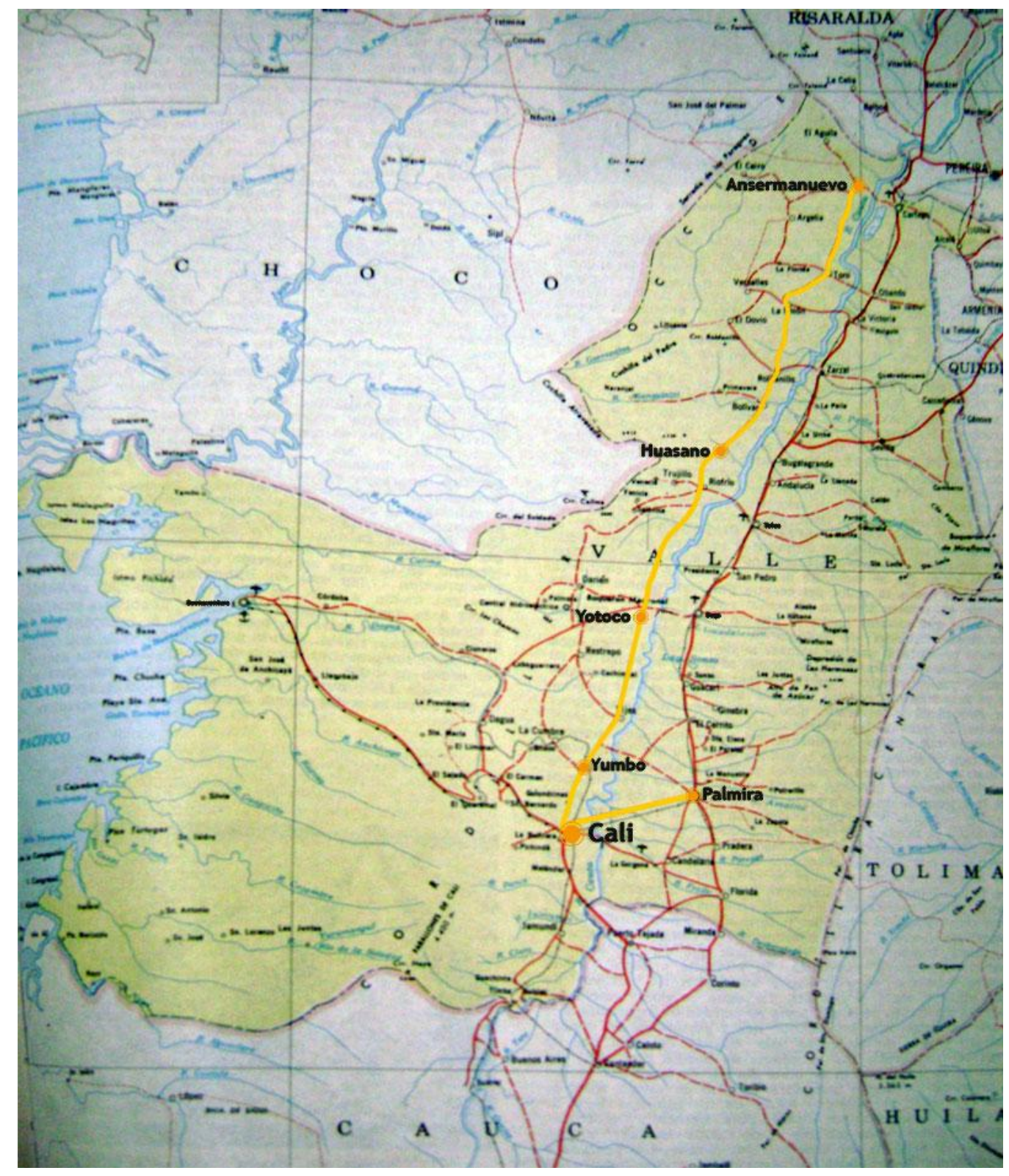


Imagen $\mathrm{N}^{\circ}$ 3: Obras con participación de cuadrillas de presos

\section{La cárcel, muchas normas y poco presupuesto}

A pesar de la copiosa reglamentación existente en la época, sobre las labores de los presos en las obras públicas y la delimitación de las funciones de la cárcel como Institución, y del trabajo como método de reforma y corrección del penado, éstos principios se vieron -enfrentados en su aplicación real- a la escasez de recursos y a la indiferencia de la clase dirigente por mejorar las condiciones de vida de los reclusos, que al fin de cuentas eran vistos como una sección social poco productiva, sin necesidad de ser tecnificada o mejorada.

En la práctica pasarían algunos años antes de lograr la construcción total del edificio penitenciario en la capital del Valle, y otros más antes de dotar de un local propio a la cárcel de mujeres en la misma ciudad. Incluso los planes para construir la penitenciaria, distaban mucho de los principios modernizantes presentes en la legislación. Mientras en países como Argentina y en ciudades como Bogotá se perseguía la edificación de presidios separados por completo de cualquier otra entidad, para generar el clima de aislamiento y seguridad requeridos por el sistema pensilvánico. En 1913, en Cali se pretendía construir un edificio de múltiples funciones, que permitiera el establecimiento no sólo de la cárcel, sino también del manicomio (AHGV, Tomo 77, p. 10). Este tipo de decisiones distaban mucho, de la intención modernizadora del legislador y permitía por el contrario la supervivencia de viejas prácticas, en las cuales se aglutinaba a los relegados sociales en un solo edificio que servía a la vez de presidio, asilo y manicomio.

Otra de las medidas presentes, en los planteamientos de la política criminal del momento, fue la reclusión separada de condenados y detenidos, como método para impedir la corrupción del inocente, pero a pesar de la ley, la falta de locales apropiados impidió el cumplimiento de éste principio (incluso hoy, en las principales cárceles del país es imposible que tal medida sea efectiva). Esta 
disposición tampoco era tenida en cuenta al conformarse los grupos de trabajo, en ellos, el interés principal estaba marcado por conocer las habilidades de los reos, para poder integrarlos a labores productivas, permitiendo así que los procesados trabajaran hombro a hombro con los ya condenados.

De otro lado, el compromiso de los gobiernos regionales con el establecimiento de la Cárcel como institución, fue en los primeros años de vida del departamento bastante débil, el Valle parecía no responder totalmente a su independencia administrativa del Cauca y de Popayán, esto se manifestó en el lento establecimiento y construcción de la cárcel de Cali, que a pesar de ser la capital del nuevo departamento continuó enviado sus presos a Popayán hasta 1911, fecha en la cual se alquiló una casa propiedad de Fortunato Garcés que de acuerdo a los contemporáneos no cumplía con los requisitos de la ley ni de la higiene (AHGV, Tomo 77, p. 10), para iniciar en años posteriores la construcción de la Cárcel del circuito de Cali, que no se concluyó sino después de 1914. Pero para éste mismo año un cambio legislativo (Ley 35 de 1914), atribuyó a la nación el servicio de cárceles, recayendo sobre ella, los gastos y la administración respectiva de las penitenciarias. Con esta nueva situación la gobernación perdió su potestad ante el sistema carcelario, para usar a los reos como miembros de cuadrillas en las obras del departamento. En 1915, el gobierno central decidió eliminar la cárcel de Cali, por economía, enviado a los presos hacia Popayán y desconociendo a la vez la recién adquirida importancia de Cali en el panorama regional.

\section{Fin de las cuadrillas de presos en el Valle}

Con la nueva legislación, se hace evidente un nuevo giro en la percepción de los grupos dirigentes, frente al trabajo sujeto que realizaban los reos, empezando a mostrarse poco convencidos de las bondades del uso de internos en la construcción de las obras públicas de la región. Ya no parecía eficaz ni importante la contribución de los reos en el desarrollo del departamento, a tal punto que, ante el planteamiento del gobierno nacional de dejar la penitenciaria de Cali a la Gobernación del Valle, para evitar el envío de los reos a Popayán, la administración regional prefirió el cierre del penal, antes de reasumir los costos del funcionamiento de la cárcel, argumentado lo siguiente: “(...)propuesta que la gobernación se apresuró a no aceptar, por saber muy bien que con trabajadores libres se obtienen obras mejores en calidad y mucho más baratas que las que rinde el trabajo forzado de los presidiarios" (AHGV, Tomo 77, p. 33).

Con esta decisión el gobierno departamental, manifestó su interés en contratar obreros libres para continuar con las obras públicas. Esta resolución de la gobernación del Valle intentaba dejar atrás una vieja figura del mundo laboral del siglo anterior, asumiendo posiciones y perspectivas como la calidad y el precio, para justificar sus decisiones administrativas, poniendo de manifiesto la llegada de un nuevo modo de concebir a la administración pública, como una institución que ante todo debía ser cada vez más competitiva y eficiente.

La dirigencia departamental argumentaba que el trabajo presidiario era una medida barata y eficaz, pero en la práctica, el número de hombres disponibles 
en las cárceles, no podía encargarse de la totalidad de las obras públicas necesarias para el buen desarrollo de los proyectos económicos regionales (entre 1912-1915 se desarrollaban al tiempo más de 30 obras públicas por año) (AHGV, Tomo 7, p. 8) por ello buena cantidad de las obras eran entregadas a particulares para su ejecución, por medio de "privilegios") (AHGV, Tomo 5, fol. $103-104,119,125)$,. De otro lado, el trabajo de los presos tampoco resultaba tan barato para las finanzas departamentales, al acaparar con el pago de raciones, más del $70 \%$ de la asignación anual destinada al Departamento de Justicia.

El trabajo de las cuadrillas de presos permanecería algunos años más, como parte de la construcción de obras públicas en el departamento del Valle, pero a partir de 1917 desaparece del Presupuesto departamental el pago de raciones de trabajo a los presos (AHGV, Tomo 79, fol. 54 - 56). En ese mismo año se prohibió la contribución del trabajo personal subsidiario (AHGV, Tomo 79, p. 28). Ambas figuras dejan de ser aplicadas en la región por ser consideradas rezagos de viejos sistemas, que debían eliminarse para dar paso a las conquistas del progreso moderno.

Con todo, el trabajo de los reclusos continuó haciendo parte de las medidas correccionales y reformadoras de la conducta de los condenados, aunque las cuadrillas de presos, fueron paulatinamente reemplazadas con la creación de talleres al interior de las penitenciarias, dejando a un lado la participación en las obras públicas y de paso aislando de nuevo a los penados en las paredes de las prisiones, invisibilizando su presencia en la sociedad.

\section{Bibliografía}

\section{Fuentes Documentales}

Concha, José Vicente. (1924). Exposición preelimar y proyecto de Código Penal. Presentado al congreso nacional en sus sesiones de 1912. Bogotá: Imprenta Nacional.

Archivo Histórico de la Gobernación del Valle del Cauca

\section{Fuentes bibliográficas}

Caimar, Lila. (2002). "Castigar Civilizadamente. Rasgos de la Modernización Punitiva en la Argentina (1827 - 1930)". En: Violencias, delitos y justicias en la Argentina. Argentina: Ediciones Manantial, Universidad Nacional de General Sarmiento. Pp.141-167.

Florez Gallego, Lenin. (1997). Modernidad Política Colombiana. El Republicanismo en el Valle del Cauca 1880-1920. Cali: Universidad del Valle. Facultad de Humanidades.

Foucault, Michel. (1981). Vigilar y castigar. México: Siglo XXI Editores.

Melo, Jorge Orlando. (1989). "De Carlos E. Restrepo a Marco Fidel Suárez. Republicanismo y Gobiernos Conservadores". En: Nueva Historia de Colombia, Vol. I. pp.215-241. Bogotá: Editorial Planeta. 
Roth, André -Noel. (1999-2000). "Ordenamiento Territorial y Descentralización: el Caso Colombiano". En: Revista Facultad De Derecho Y Ciencias Políticas Y Sociales. Vol. 3. pp. 51-66

Saenz Obregón Javier, saldarriaga Oscar, ospina Armando. (1997). Mirar la infancia Vol II.: pedagogía, moral y modernidad en Colombia, 1903 -1946. Bogotá: Ediciones Uniandes.

Valencia Llano, Alonso. (1993). Empresarios y políticos en el estado soberano del Cauca 1860-1895. Cali: Facultad de Humanidades, Universidad del Valle.

Velez, Humberto. (1993). "Desarrollo Económico y Consolidación Política del Valle del Cauca 1880-1910". En Historia regional del Valle del Cauca. Cali: Universidad del Valle. pp.171-189.

Recibido: 16 de mayo de 2010

Aprobado: 18 de noviembre de 2010 
